\title{
Planning Future Electric Vehicle Central Charging Stations Connected to Low-Voltage Distribution Networks
}

\author{
Marra, Francesco; Træholt, Chresten; Larsen, Esben
}

Published in:

3rd International Symposium on Power Electronics for Distributed Generation System

Publication date:

2012

Link back to DTU Orbit

Citation (APA):

Marra, F., Træholt, C., \& Larsen, E. (2012). Planning Future Electric Vehicle Central Charging Stations Connected to Low-Voltage Distribution Networks. In 3rd International Symposium on Power Electronics for Distributed Generation System IEEE.

\section{General rights}

Copyright and moral rights for the publications made accessible in the public portal are retained by the authors and/or other copyright owners and it is a condition of accessing publications that users recognise and abide by the legal requirements associated with these rights.

- Users may download and print one copy of any publication from the public portal for the purpose of private study or research.

- You may not further distribute the material or use it for any profit-making activity or commercial gain

- You may freely distribute the URL identifying the publication in the public portal

If you believe that this document breaches copyright please contact us providing details, and we will remove access to the work immediately and investigate your claim. 


\section{Planning Future Electric Vehicle Central Charging Stations Connected to Low-Voltage Distribution Networks}

\author{
Francesco Marra \\ Electrical Engineering Department \\ Technical University of Denmark \\ 2800 Kongens Lyngby, Denmark \\ fm@elektro.dtu.dk
}

\author{
Chresten Træholt and Esben Larsen \\ Electrical Engineering Department \\ Technical University of Denmark \\ 2800 Kongens Lyngby, Denmark
}

\begin{abstract}
A great interest is recently paid to Electric Vehicles (EV) and their integration into electricity grids. EV can potentially play an important role in power system operation, however, the EV charging infrastructures have been only partly defined, considering them as limited to individual charging points, randomly distributed into the networks. This paper addresses the planning of public central charging stations (CCS) that can be integrated in low-voltage (LV) networks for EV parallel charging. The concepts of $\mathrm{AC}$ and DC architectures of CCS are proposed and a comparison is given on their investment cost. Investigation on location and size of $\mathrm{CCS}$ is conducted, analyzing two LV grids of different capacity. The results enlighten that a public CCS should be preferably located in the range of $100 \mathrm{~m}$ from the transformer. The $\mathrm{AC}$ charging levels of $11 \mathrm{~kW}$ and $22 \mathrm{~kW}$ have the highest potential in $\mathrm{LV}$ grids. The option of DC fast-charging is only possible in the larger capacity grids, withstanding the parallel charge of one or two vehicles.
\end{abstract}

Keywords - electric vehicles, charging insfrastructures, charging stations, low voltage grids

\section{INTRODUCTION}

I N 2008, the European Commission published the "20 20" by 2020 package. The aim is to reach reduced greenhouse gas emissions and to increase generation from renewable power sources [1]. A possible way for achieving the Commission targets is given by the combination of batterypowered vehicles, or simply EVs, and the charging infrastructures. In fact, in the process of electrification of transport sector, the infrastructure is going to play a major role. Until few years ago, EV infrastructures were seen as limited to single charging points in urban streets or parking lots, with little or no attention to their grid operation [2]. With more EVs coming on the market, the attention for infrastructures has increased, leading also to different charging concepts.

The standard way of charging an EV, originally known as slow charging option, has lately involved the opportunity of managing the charging process with communication technologies that enable a remote control [3]. This is possible by controlling a single charging spot, or the vehicle management system (VMS), if such intelligent equipment is available. The need for an EV range extension and the necessity of a short waiting time for charging pushed EV manufacturers to implement the fast-charging option for EVs. Fast charging, or DC charging, is investigated in [4]. The third concept of EV charging is based on the battery switch station; in [5], the authors described the concept and possible solutions for the charging management of a cluster of batteries.

The gradual replacement of internal combustion engine (ICE) cars with EVs requires a more scrupulous planning of future charging infrastructures in LV distribution grids, not only limited to single charging points, but extended to the level of public central charging stations (CCS). With more EVs on the market, such CCS are expected to have automated functions that allow parallel charging and different charging power levels.

Furthermore, the planning of a CCS should take into account the different grid constraints in LV grids. In fact, such infrastructures, likewise gas stations, are likely to be located at strategic points of urban areas which are suitable to EV users. In the integration process, it should be ensured that the grid voltage and the components loading such as LV cables and transformers stay within their allowed range.

In this paper, different concepts of CCS to accommodate EV charging in LV distribution networks are proposed. The location and size for such infrastructures are identified for two LV grids of different capacity. Finally, a cost analysis for the different concepts of CCS is performed.

\section{EV CHARGING}

In the planning of a CCS, an important aspect to consider is the charging power defined in the common developed standards.

The actual status for EV conductive charging in Europe is defined in the IEC 61851-1 [6]. The standardization activity has focused on electric vehicle requirements for conductive charging with AC and DC supply. The different AC and DC charging options are depicted in Table I, for reference. The quick charging power levels of $22 \mathrm{~kW}$ and $43 \mathrm{~kW}$ will be accommodated gradually in three phases: the $22 \mathrm{~kW}$, defined in IEC 61851 - Mode 2, will be deployed first; the second phase will involve the $43 \mathrm{~kW}$ charging power, defined in Mode 3, while the third phase will involve Mode 4 charging or DC charging, which entails next generation batteries requiring at least $60 \mathrm{~kW}\left(400 \mathrm{~V}_{\mathrm{dc}}-150 \mathrm{~A}\right)$ charging power; with this case, a

The authors are grateful to the financial support from the Danish project "Electric Vehicles in a Distributed and Integrated Market using Sustainable Energy and Open Networks", EDISON, which was funded by the ForskEl program (ForskEl Project Number 081216) 
$20 \mathrm{kWh}$ battery pack can be charged up to $80 \%$ state-of-charge (SOC) in about 15 minutes [7].

From a CCS perspective, the main difference between Mode 3 and Mode 4 is that, with Mode 3, there is the option of charging an EV with $\mathrm{AC}$ power of up to $43 \mathrm{~kW}$, if a vehicle on-board charger with same power is available; with Mode 4, the CCS should be capable of fast-charging using a stationary off-board DC charger.

One major requirement for CCS design is therefore the capability to provide AC or DC power for charging, depending on the desired charging time and based on the EV charging capabilities.

Table I

Charging power options

\begin{tabular}{ccccc}
\hline & Current & Voltage & Grid connection & Power \\
\hline & $16 \mathrm{~A}$ & $230 \mathrm{~V}$ & single phase & $3.7 \mathrm{~kW}$ \\
& $32 \mathrm{~A}$ & $230 \mathrm{~V}$ & single phase & $7.4 \mathrm{~kW}$ \\
$\mathrm{AC}$ & $16 \mathrm{~A}$ & $400 \mathrm{~V}$ & three-phase & $11 \mathrm{~kW}$ \\
& $32 \mathrm{~A}$ & $400 \mathrm{~V}$ & three-phase & $22 \mathrm{~kW}$ \\
& $63 \mathrm{~A}$ & $400 \mathrm{~V}$ & three-phase & $43 \mathrm{~kW}$ \\
\hline DC & $150 \mathrm{~A}$ & $400 \mathrm{~V}$ & off-board charger & $60 \mathrm{~kW}$
\end{tabular}

\section{A. Combo plug for $A C$ and DC charging}

The physical interface for transferring AC or DC power to the vehicle is defined in the Standard IEC 62196-3 [8]. This standard defines the contact coupler for DC charging, to be used under Mode 4 charging, according to IEC 61851-1. Though the publication of the standard is expected in

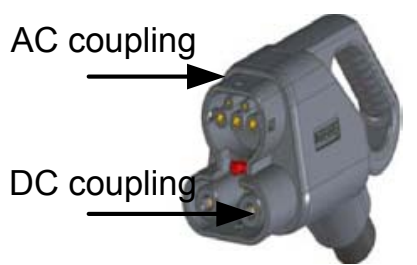

Fig. 1. "Combo" charging plug for EVs, based on IEC 62196-3 [9]

December 2013, the proposal from this standardization activity represents an important step towards the design of CCS architectures. The proposed coupler, Fig. 1, is also known as "combo" as it allows both AC and DC charging, embedded on the same charging cable [9].

Other ways of fast-charging or DC charging have been developed, where the AC inlet is completely decoupled from the DC inlet [10]. In this case, two different charging cables are required.

\section{INTEGRATION OF EVS IN LV GRIDS}

Urban grids have a high potential for CCS integration, due to the proximity to houses and parking lots. An optimal placement of public CCS shall minimize the distance driven for recharging the vehicles. However, depending on location and distance from the LV transformer, a CCS can have different impacts on the grid voltage and on components loading. For this reasons, different grid constraints should be taken into account when dealing with CCS planning.

\section{A. Voltage constraints for CCS planning}

LV grids are mainly composed of radial feeders and cables with high $\mathrm{R} / \mathrm{X}$ ratio. A typical residential LV grid with a 100 $\mathrm{kVA}$ secondary distribution transformer and two $95 \mathrm{~mm}^{2}$ main feeders rated at $230 \mathrm{kVA}$ [12], is depicted in Fig. 2, and considered as case of study. The nomenclature used (e.g. A,2), indicates the electric cabinet ID and the number of connected households respectively. One of the issues limiting the load in $\mathrm{LV}$ grids is the voltage drop along the different feeders. The voltage in a LV grid is function of the following factors, among all:

- LV components characteristics: cables length, cross section and capacity, cable impedance etc.

- Operational characteristics: tap-changer position in secondary distribution transformers, voltage limits set by the local DNO etc.

- Load profiles: loads at each node in the grid etc.

Table II

Assumptions for maximum load calculation

\begin{tabular}{c|c|c}
\hline Cases & Base grid voltage & $\begin{array}{c}\text { Minimum allowed } \\
\text { voltage }\end{array}$ \\
\hline Case 1 & 1.00 p.u. & 0.90 p.u. \\
Case 2 & 1.04 p.u. & 0.90 p.u. \\
Case 3 & 1.00 p.u. & 0.95 p.u. \\
Case 4 & 1.04 p.u. & 0.95 p.u. \\
\hline
\end{tabular}

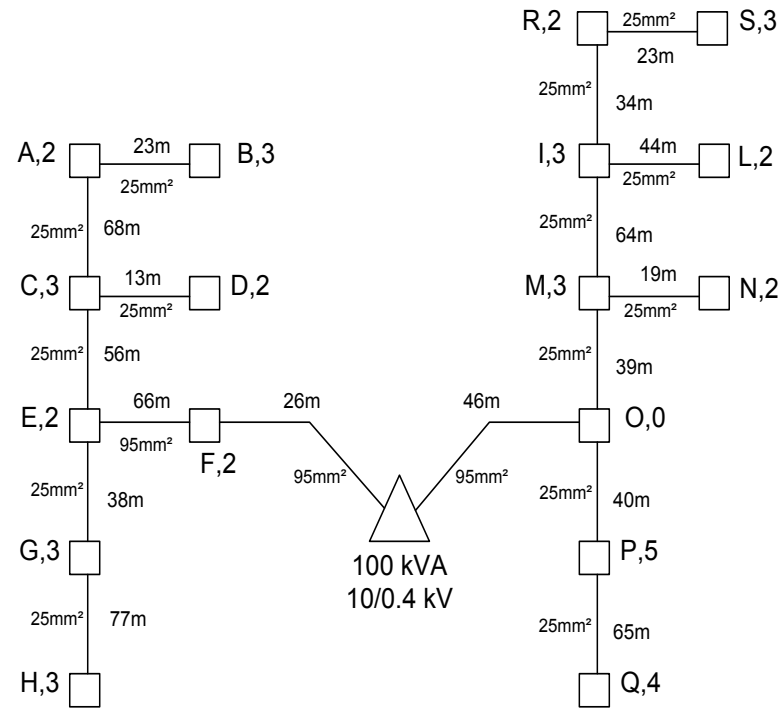

Fig. 2. Residential LV grid

For the LV in Fig. 2, it is possible to calculate the maximum load that does not exceed the minimum voltage level $\mathrm{V}_{\text {min }}$ required at the different terminals in the grid. The 


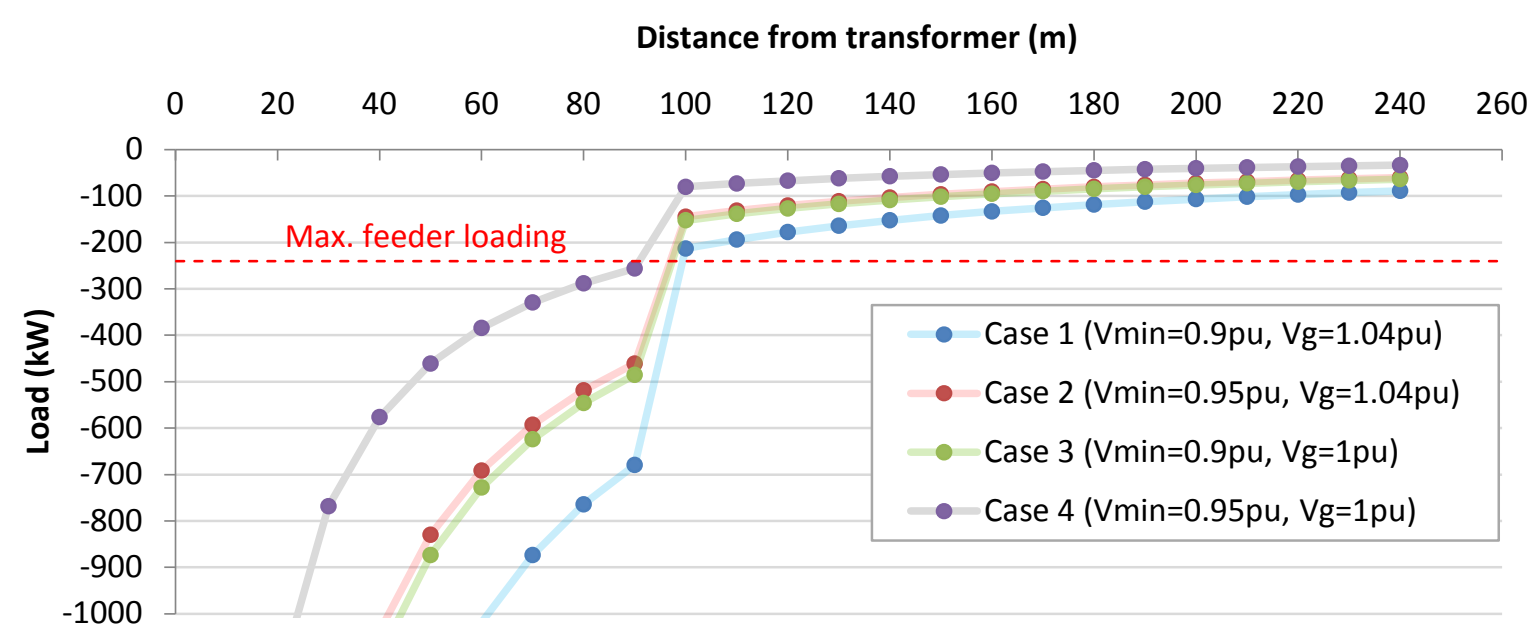

Fig. 3. Maximum load in relation to different operating conditions

calculation is performed according to the four cases of Table II, where two different values of base grid voltage $V_{g}$ and minimum voltage $\mathrm{V}_{\min }$ are considered.

The base grid voltage $\mathrm{V}_{\mathrm{g}}$ is assumed 1.04 p.u. and 1.0 p.u. respectively, considering two possible operational set-points by the local DNO. As minimum voltage level $\mathrm{V}_{\min }$ in the grid, 0.9 p.u. is assumed first, according to the voltage requirement by the standard EN 50160. Then, a minimum voltage of 0.95 p.u. is considered, taking as reference the design guidelines of a typical Danish LV grid [11].

Based on the assumptions made, the four power curves of Fig. 3 can be obtained according to [13], considering a threephase load scenario using :

$$
P \cdot l=3 \frac{\left(V_{\min }-V_{g}\right) \cdot V_{\min }}{Z}
$$

where $Z \quad$ is the cable impedance in $\Omega / \mathrm{m}$

$l \quad$ is the distance from the transformer

$P \quad$ is the power per unit length

In the range of $100 \mathrm{~m}$ from the transformer, Fig. 3, it is possible to observe that the network loading is mainly limited by the maximum $95 \mathrm{~mm}^{2}$ cable capacity, since a high load is possible without reaching the minimum voltage level $\mathrm{V}_{\min }$. The curve of Case 1 is the best case for loads, due to the highest base grid voltage and lowest voltage $\mathrm{V}_{\min }$ of 0.9 p.u. Case 2 and Case 3 lead to very similar power curves, though they refer to quite different operational conditions. Case 4 depicts the most restrictive case for load power, due to a narrower operational voltage window, compared to the other cases. However, with an increasing distance from the transformer, the maximum load in the grid is limited by the voltage requirement, for all cases.

Considering that the load in the grid shall comprise the original residential load and the new CCS load, the voltage drop along the feeder cannot be entirely allocated to EV charging purposes. For this reason, the assumption of $\mathrm{V}_{\min }=0.95$ is taken, reserving the remaining voltage drop to the existing loads. Furthermore, a base grid voltage $\mathrm{V}_{\mathrm{g}}$ of 1.04 p.u. is considered at the transformer secondary side.

\section{B. Components load constraints for CCS planning}

The limit of feeder cable loading has been already considered in the CCS planning. The sizing aspects of CCS shall be also put in relation to the characteristics of typical LV distribution transformers. Two residential grids with transformer capacity of $100 \mathrm{kVA}$ and $630 \mathrm{kVA}$ respectively are taken into account for comparison.

For the grids, the loads were modeled considering real measurements for a $0.4 \mathrm{kV} \mathrm{LV}$ feeder. The simulation results of the study in [14] are taken as reference for estimating the transformer power allocation for a CCS. In [14], it was considered that the most critical situation of EV charging is the "dumb" charging scenario, where all vehicles can start or stop charging without coordination. This critical scenario was simulated during electricity peak-hours, i.e. from about 5 p.m. till 10-11 p.m. A definition of EV penetration was given, referring to the ratio between the total loading due to $\mathrm{EV}$ charging over the nominal transformer capacity and it was determined that an EV penetration of $20 \%$ is possible, without overloading the transformer. In support to this result, the findings of Clement-Nyns et $\mathrm{Al}$. in [15] were considered. According to [15], 20-25\% of EV penetration is possible in actual grids, without exceeding the voltage limits of Standard EN 50160 [16] and the transformer ratings.

A penetration level of $20 \%$ is therefore considered as design parameter for the power allocation of a CCS, in this paper. For the two analyzed grids, the CCS capacity is therefore indicated in Table III.

Table III

CCS size

\begin{tabular}{c|c|c}
\hline Grid capacity & Allowed penetration level & $\begin{array}{c}\text { Power allocated } \\
\text { for CCS }\end{array}$ \\
\hline $100 \mathrm{kVA}$ & $20 \%$ & $20 \mathrm{kVA}$ \\
\hline $630 \mathrm{kVA}$ & $20 \%$ & $126 \mathrm{kVA}$ \\
\hline
\end{tabular}




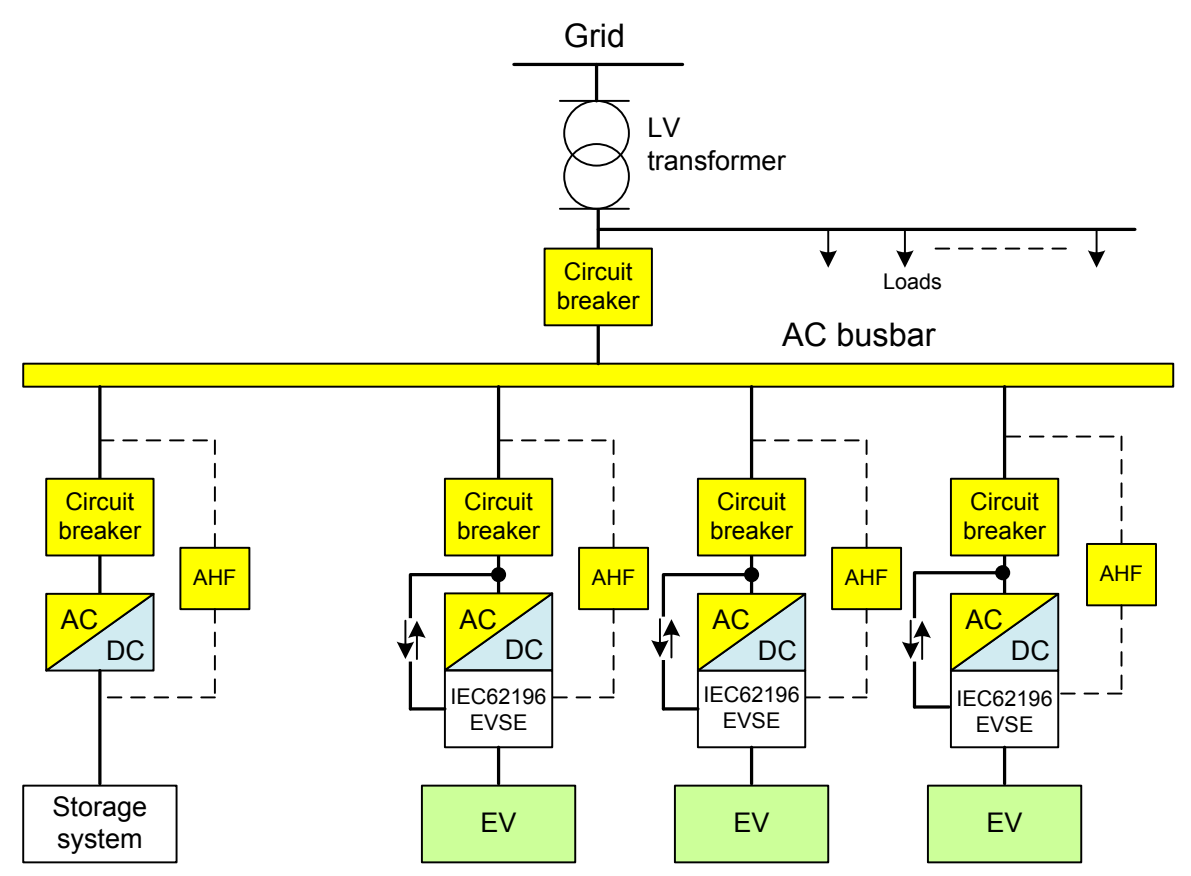

Fig. 4. AC-distribution CCS architecture

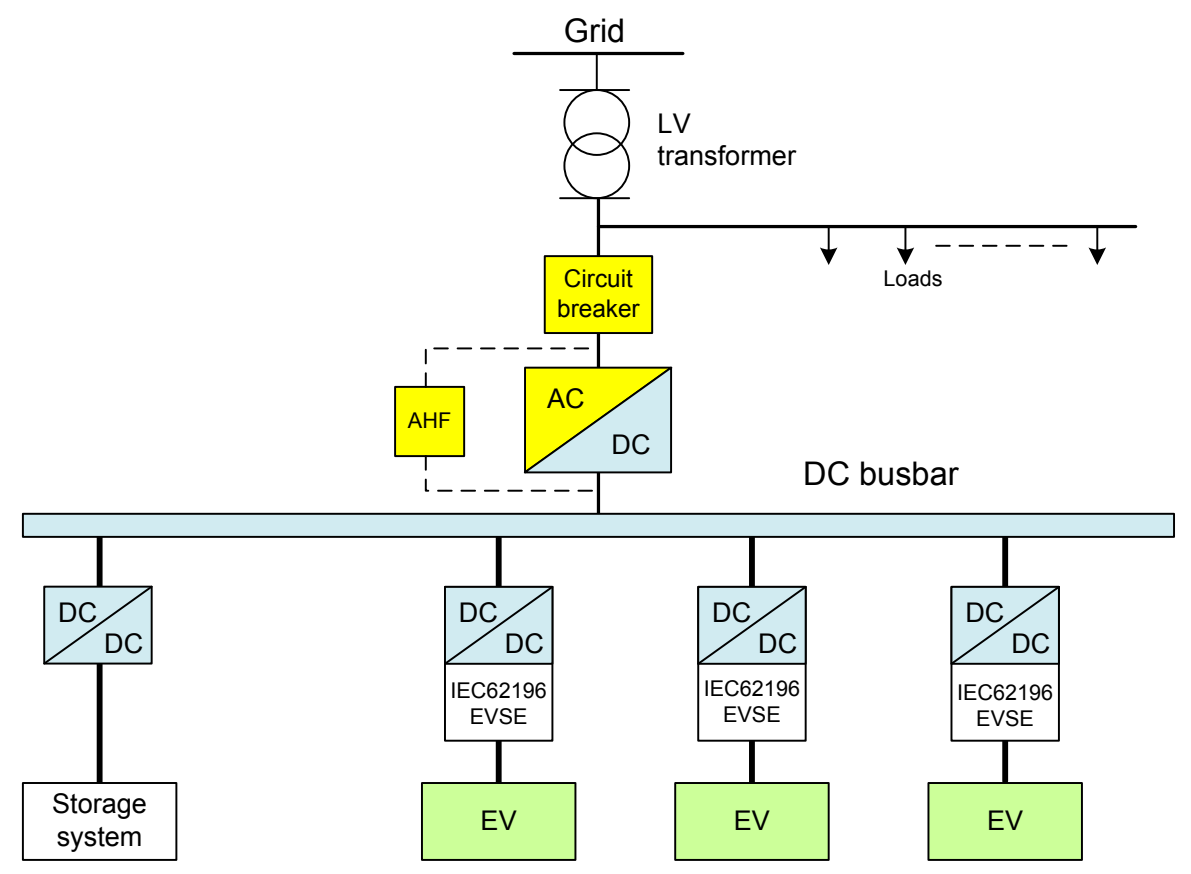

Fig. 5. DC-distribution CCS architecture

\section{Central Charging Station CONCEPTS}

The first defined concept is the AC-distribution CCS concept, Fig. 4. The CCS is connected to a $10 / 0.4 \mathrm{kV} \mathrm{LV}$ transformer, by means of a main AC circuit breaker. The CCS capacity is limited by the transformer capacity, which in this paper is considered $100 \mathrm{kVA}$ or $630 \mathrm{kVA}$. The second concept proposed is the DC-distribution CCS, Fig. 5. The possibility of fast-charging an EV battery using off-board DC chargers [7] and the reduced charging time are the main features of the second concept of CCS. 


\section{A. Comparison of CCS architectures}

In both concepts, the CCS is energized by a $0.4 \mathrm{kV}$ feeder, connected to the LV distribution transformer. A main circuit breaker ensures disconnection to the CCS whenever required.

After the AC breaker, each CCS is characterized of different electrical and power electronics components.

In the $A C$-distribution $\mathrm{CCS}$, the power distribution is realized with AC busbar which supplies each terminal involved in the EV charging. Secondary circuit breakers are used for coupling between the busbar and the different charging terminals (EV supply equipment, EVSE). Since the power can follow two different paths, according to the architecture, both $\mathrm{AC}$ and $\mathrm{DC}$ charging are possible. The first one, indicated by arrows in Fig. 4, is the AC charging option: the power is derived after the AC breaker and conducted till the EVSE. The AC charging power options of Table I are valid under this use case and apply depending on the vehicle on-board charger capabilities. It is worthwhile noticing that under the AC charging case, the power path can be bidirectional, as inherently possible by the electrical CCS components. Of course, this requires a vehicle bidirectional charger. The case of reverse power flow, from EV to grid, is known as Vehicle-to-Grid mode [17], and for that, the same power levels described in Table I apply. Each EVSE is capable of AC and DC charging. Under DC mode, an AC/DC power converter rectifies the $\mathrm{AC}$ voltage/current and controls the charging current, by means of a DC/DC power converter; these two components can be seen as aggregated into a single charging unit. The interface with the vehicle is assumed to be realized through the EVSE, according to IEC 62196-3 [8].

Different power quality issues arise while charging an EV. Among all, harmonics and voltage variations are among the major issues. Orr et $\mathrm{Al}$. in [18] presented results on harmonics due to EV charging; the main recommendation suggested is to filter harmonics and staying away from the limits emanated in the relative standard. At the scope, an active harmonic filter (AHF) is planned between the EVSE output and the point of common coupling with the AC busbar. Furthermore, a stationary energy storage system is added to the CCS hardware, to operate during transient events, e.g. switching on or off one or more power converters involved in DC charging [19].

In the $D C$-distribution $\mathrm{CCS}$, Fig. 5, the architecture differs from the first one, after the main $\mathrm{AC}$ circuit breaker. In this case, a main AC/DC power converter is designed to supply power to the entire station. As this converter is not supposed to work continuously at its rated power, it should be accurately designed depending on the number of vehicles that can charge simultaneously. The power distribution to all charging terminals is realized with a DC busbar. On each terminal, a $\mathrm{DC} / \mathrm{DC}$ converter is used for controlling the charging power level. Also in this case, an IEC62196-3 compatible EVSE is the required physical interface to the vehicle. With this CCS, harmonics problems are mitigated by a centralized AHF connecting between the LV feeder and the primary AC/DC converter.

\section{RESULTS}

\section{A. CCS location and size}

The location aspect for a CCS has enlightened that its installation in the proximity of the LV grid transformer, i.e. in the range of $100 \mathrm{~m}$, can minimize voltage magnitude problems. The placement of a CCS in the grid is therefore assumed in the range of $100 \mathrm{~m}$ from the transformer.

The planning of the size should take into account the number of EVs that can potentially charge simultaneously in a CCS, for this we referred to the scenarios illustrated in Table II. The possible number of EVs charging simultaneously is estimated for both grids of $100 \mathrm{kVA}$ and $630 \mathrm{kVA}$ and the results are summarized in Table III. Considering the larger grid and the power allocation scenarios of Table II, it is possible to have $5 \mathrm{EVs}$ charging with $22 \mathrm{~kW}$ or $2 \mathrm{EVs} \mathrm{DC}$ charging with $60 \mathrm{~kW}$ each. Therefore, both AC and DC charging are possible in the large grid. Within the $100 \mathrm{kVA}$ grid, DC charging is not possible, while AC charging with a power a level of $11 \mathrm{~kW}$ is found to be an option.

Table III

Parallel charging options in the two LV grids

\begin{tabular}{c|c|c|c}
\hline Power & $\begin{array}{c}\text { Charging } \\
\text { option }\end{array}$ & $\begin{array}{c}\text { 100 kVA } \\
\text { grid }\end{array}$ & $\begin{array}{c}\text { 630 kVA } \\
\text { grid }\end{array}$ \\
\hline $11 \mathrm{~kW}$ & $\mathrm{AC}$ & 1 & 11 \\
\hline $22 \mathrm{~kW}$ & $\mathrm{AC}$ & 0 & 5 \\
\hline $43 \mathrm{~kW}$ & $\mathrm{AC}$ & 0 & 2 \\
\hline $60 \mathrm{~kW}$ & $\mathrm{DC}$ & 0 & 2 \\
\hline
\end{tabular}

\section{B. Cost estimation of CCS concepts}

The power components cost for both CCS architectures is estimated and a comparison on the initial investment is performed for both the CCS. At the scope, the project report by Kristensen et $A l$. is considered as reference. The report is a deliverable of the Work Package 4, WP4, of the Danish Edison project [20].

In Table IV, the components cost is shown for both CCS. The grid connection cost is estimated at $5 € / \mathrm{kW}$ for both CCS and it is not indicated in Table IV.

To ensure flexibility of operation between AC and DC charging, the EVSE in the AC-distribution CCS are planned according to the IEC 61851-1 Mode 3 [6], which allows AC or DC charging with $400 \mathrm{~V}_{\mathrm{dc}}, 250 \mathrm{~A}_{\mathrm{dc}}$, while only DC charging is possible in the second CCS.

In Table IV, results on investments estimation are shown. For the two different CCS, with equivalent power allocation, the additional flexibility offered by AC-distribution CCS shows a higher initial investment. This is due to more components than an equivalent size DC-distribution CCS. However, the flexibility offered by the AC-distribution CCS, for AC or DC charging, has itself an intrinsic economic impact that should be separately evaluated. With the actual EV on the market, having only few of them designed with DC charging capability, a best guess could be that an AC-distribution CCS 
Table IV

Estimation of investment cost for the AC and DC distribution CCS

\begin{tabular}{c|cc|cc} 
& \multicolumn{2}{|c|}{ AC-distribution CCS } & \multicolumn{2}{c}{ DC-distribution CCS } \\
\hline Component & Cost $€$ & Q.ty & Cost $€$ & Q.ty \\
\hline AC Busbar & $\begin{array}{c}2851 \\
\text { (per terminal) }\end{array}$ & 5 & - & - \\
DC Busbar & - & - & (per terminal) & 2 \\
Main AC/DC & - & - & 12,000 & 1 \\
converter & - & 5 & - & - \\
AC/DC \\
converter & 6000 & 5 & 3000 & 2 \\
EVSE & 3000 & - & 6000 & 2 \\
$\begin{array}{c}\text { DC/DC } \\
\text { converter }\end{array}$ & - & 1 & 2000 & 1 \\
Main AC breaker & 2000 & 5 & - & - \\
Sec. AC breaker & 2000 & & $37668 €$ & \\
\hline Tot. & $71255 €$ &
\end{tabular}

would have a higher utilization factor than a DC-distribution CCS.

\section{CONCLUSIONS}

Two different CCS concepts were presented, namely the AC-distribution and DC-distribution CCS. The first one offers more flexibility as it permits both $\mathrm{AC}$ and $\mathrm{DC}$ charging to $\mathrm{EV}$, though the investment cost results higher for the same installed power. In the DC-distribution CCS concept, charging is possible only if EVs are capable of DC charging.

The planning of public CCS in LV grids should take into account voltage and components loading requirements. To limit voltage variations, a CCS should be planned in the proximity of the LV transformer. The size of a CCS can be limited by transformer capacity and LV cables loading. The quick charging options of 11 and $22 \mathrm{~kW}$ are likely in urban LV grids within an AC-distribution CCS. DC charging up to $60 \mathrm{~kW}$ can be implemented in large LV grids in the proximity of LV transformers, allowing the simultaneous charging of up to 2 vehicles.

\section{REFERENCES}

[1] European Commission, "20 20 by 2020 Europe's climate change opportunity", COM (2008) 30 final, Brussels, 2008.

[2] J. G. Ingersoll, C. A. Perkins, "The $2.1 \mathrm{~kW}$ photovoltaic electric vehicle charging station in the city of Santa Monica, California", in IEEE Proc. on Photovoltaics Specialists Conference, 1996.

[3] D. Benzai, W. Zhiqiang, "Research on Electric-Vehicle Charging Station Technologies Based on Smart Grid", in Proc. of Power and Energy Engineering Conference (APPEEC), Asia-Pacific, 2011.

[4] D. Aggeler, F. Canales, H. Zelaya - De la Parra, A. Coccia, N. Butcher, and O. Apeldoorn, "Ultra-Fast DC-Charge Infrastructures for EVMobility and Future Smart Grids", in Proc. of IEEE-PES Innovative Smart Grid Technologies Conference Europe (ISGT Europe), 2010.
[5] H. Yudai, and K. Osamu, "A Safety Stock Problem in Battery Switch Stations for Electric Vehicles", in Proc. of The Eighth International Symposium on Operations Research and Its Applications (ISORA'09), 2009

[6] IEC 61851-1.

[7] Thunder Sky, LFP Battery User Manual.

[8] IEC 62196-3.

[9] Vattenfall, "Standardization of Fast Charging equipment for Electric Vehicles", online.

[10] Nissan Leaf Specs, "Charging”, online, 2012.

[11] SEAS-NVE, "Design manual for $10 \mathrm{kV}$ and $0.4 \mathrm{kV}$ ", Denmark.

[12] NKT Cables, Low voltage cables, 2012, online catalogue.

[13] C. Debruyne, J. Desmet, J. Vanalme, B. Verhelst, G. Vanalme, and L. Vandevelde, "Maximum power injection acceptance in a residential area", in conf. proc. of International Conference on Renewable Energies and Power Quality (ICREPQ'10), Granada (Spain), 2010.

[14] F. Marra, M.M. Jensen, R. G. Valle, C. Træholt, E. Larsen, "Power Quality Issues into a Danish Low-Voltage Grid with Electric Vehicles", in Proc. of IEEE 11th International Conference on Electric Power Quality and Utilization (EPQU), Lisbon, Portugal, 2011.

[15] K. Clement-Nyns, E. Haesen and J. Driesen, "The Impact of Charging Plug-In Hybrid Electric Vehicles on a Residential Distribution Grid", IEEE Transactions on Power Systems, Vol. 25, No. 1, February 2010.

[16] Standard EN 50160.

[17] W. Kempton and J. Tomic, "Vehicle-to-grid power fundamentals: Calculating capacity and net revenue", in J. Power Sources, vol. 144, no. 1, pp. 268-279, Jun. 2005

[18] J. A. Orr, A. E. Emanuel, D. J. Pileggi, "Current Harmonics, Voltage Distortion, and Powers Associated with Electric Vehicle Battery Chargers Distributed on the Residential Power System", in IEEE Transactions on Industry Applications, Vol. IA-20, No. 4, pp. 727-734, 1984.

[19] I. S. Bayram,G. Michailidis, M. Devetsikiotis; S. Bhattacharya, A. Chakrabortty, and F. Granelli, "Local energy storage sizing in plug-in hybrid electric vehicle charging stations under blocking probability constraints", in Proc. of IEEE Smart Grid Communications Conf. (SmartGridComm), 2011.

[20] S. L. Kristensen, A. Foosnæs, P. Nørgård, O. Gehrke, A. Schmitt, "Concept study on fast charging station design", Project Edison - WP4.5 report, public report. 